\title{
BIBLIOGRAFIA
}

\section{Bibliografía de Ignacio Rodríguez Galván}

$$
\text { (1816-1842) }
$$

\section{Guia de su producción literaria y su biografia}

Bastante se ha escrito sobre los orígenes del romanticismo en México, y no sin apreciar a Ignacio Rodríguez Galván como voz fresca y violenta del movimiento, en sus principios. Pero a pesar de cuanto se le ha dedicado de crítica y de biografía, queda todavía por hacer de él una biografía adecuada y una critica circunspecta. No ha sido esto por falta de buenos especialistas en una y otra materia, sino por la carencia de una noción exacta de lo que Rodríguez Galván escribió y de lo que de él se sabía. Han pasado cien años desde la fecha de la muerte del poeta; sin embargo, hasta ahora no han sido estudiadas ni su obra ni su vida desde el punto de vista bibliográfico. Hacemos una primera tentativa, para "enderezar el entuerto" y a la vez rendir homenaje a su memoria en el centenario de su muerte, con este pequeño estudio.

Merece nota especial un artículo costumbrista intitulado "Un coplero mejicano del siglo xix", fechado el 19 de octubre de 1837 y publicado en el Año Nuevo de 1838. Aunque no lleva su firma, es sin duda de Rodríguez Galván. Retrato fiel del poeta romántico de la época, viene a ser también un manifiesto importante, en el cual se afirma por primera vez el derecho a ser de la escuela romántica mexicana. Aquí está presente el coplero, el verdadero poeta, el "hombre sensible" que escribe versos con pluma fecundada con la sangre propia que la moja. "Su corazón padece, su corazón le dicta las pala- 
bras"... "Querría el poeta huir de la sociedad que detesta", de los críticos que "le mofan y le atormentan, y le desesperan". Querría. mejor ser trovador de los tiempos antiguos, cuando con puñal y laúd se podía ir a cantar trovas de castillo en castillo, bañado por la claridad de un oficio noble y aplaudido. Pero el poeta - -y claro que en. todo el artículo Galván se describe a sí mismo- no se escapa ni de las durezas de la vida social, ni de las añoranzas del mundo interior. Convierte el calor de sus padecimientos en luz que ilumina, para sí y para sus prójimos, las recónditas bellezas del sentir humano. La. nobleza a que aspira le viene de la que crea en su poesía.

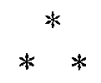

Esta bibliografía se divide en ocho secciones, en todas las cuales, menos en la última, cada entrada tiene su número.

Secciones

1. Colecciones

2. Obras que editó

3. Obras dramáticas

4. Poesías

5. Novelas y cuentos

6. Artículos varios

7. Traducciones

Números

$$
\begin{array}{rll}
1 & \text { a } & 3 \\
4 & \text { a } & 14 \\
15 & \text { a } & 21 \\
22 & \text { a } & 77 \\
78 & \text { a } & 95 \\
96 & \text { a } & 101 \\
102 & \text { a } & 118
\end{array}
$$

8. Obras críticas y biogtráficas referentes a Rodríguez Galván.

Como no pocas de las obras citadas son raras y difíciles de localizar, se ha creído útil hacer constar las bibliotecas mexicanas y norteamericanas que poseen ejemplares de ellas. Los símbolos del Catálogo de la Unión Panamericana, de Washington, D. C., se han empleado para designar las bibliotecas en los Estados Unidos; otros símbolos, inventados según el mismo sistema, se refieren a las bibliotecas de México.

\section{Clave de las bibliotecas}

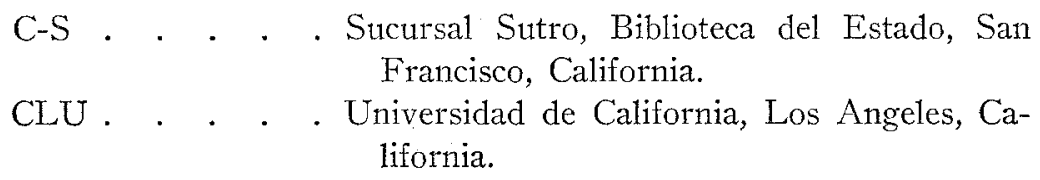


$\mathrm{CoDu}$. . . Universidad de Denver, Denver, Colorado. $\mathrm{Cu}-\mathrm{B}$. . . . Biblioteca Bancroft, Universidad de California, Berkeley, California.

DLC . . . . Biblioteca del Congreso, Washington, D. C.

EM . . . . Biblioteca del autor.

$\mathrm{IaU}$. . . . . Universidad de Iowa, Iowa City, Iowa.

ICN . . . . Biblioteca Newberry, Chicago, Illinois.

LNT . . . . Universidad de Tulane, New Orleans, Louisiana.

MxF . . . . Biblioteca Nacional, México, D. F.

MxFI . . . Biblioteca Iberoamericana, México, D. F.

MxFU ... . Universidad Nacional de México, México, D. F.

MxI . . . . Biblioteca del Estado, Guadalajara, Jalisco.

MixMi . . . Biblioteca del Estado, Morelia, Michoacán.

$\mathrm{MxZ}$. . . . . Biblioteca del Estado, Zacatecas, Zacatecas.

NN . . . . Biblioteca Pública, New York, New York.

NNH . . . Hispanic Society, New York, New York.

NRU . . . . Universidad de Rochester, Rochester, New York.

TxU . . . . . Universidad de Texas, Austin, Texas.

ViU . . . . . Universidad de Virginia, University, Virginia.

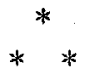

\section{COLECCIONES}

1. Poesías / de / d. Ignacio Rodriguez Galvan. / Tomo I. / Composiciones líricas originales. / [orn.] / Mejico: 1851. / [pleca] / Impresas por Manuel N. de la Vega. / Calle de Santa Clara núm. 23. /

Portada, v. bl.; p. [2] Al lector, firmado por Antonio Rodríguez Galván, hermano del poeta; [2] bl.; 1-311 texto; [2] índice de títulos de poemas. Tomo $2^{\circ}$ : Portada con estos cambios, "Tom. Ir. / Composiciones dramáticas originales."; v. bl.; p. 3-336 texto; [2] índice, v. bl. $4^{\circ} 236 \times 148 \mathrm{~mm}$. Como frontispicio del primer tomo, un retrato del autor.

Siendo una colección formada por el hermano del autor, es muy importante como guia de las obras auténticas de éste. Como el poeta no siempre firmó sus producciones es sumamente difícil, probablemente imposible, identificar todo lo suyo publicado en las revistas literarias de aquella época. Con- 
tiene el $2^{\circ}$ tomo de esta colección La capilla, Muñoz visitador de Méjico y El privado del virrey. Aunque ya en julio de 1843 se anunció esta primera edición como "en prensa", no se logró darla a luz hasta 1851 . Véase la página 24 del segundo tomo del Museo mexicano.

Ejemplares: CLU, MxF, MxFU, MxJ, MxMi, NNH, TxU.

2. Obras / de / d. Ignacio Rodríguez / Galván. / [pleca] / I. / Composiciones líricas originales. / [pleca] / México. / Imprenta de J. R. Barbedillo y $C^{2}$ Escalerillas núm. 21/[pleca] / 1876. /

Portada, v.: "Edición de 'La Voz de México" "; p. [1] 4-7. Al lector, firmado por Antonio Rodríguez Galván; 8-495 texto; [4] índice. Tomo $2^{\circ}$. Portada con este cambio: "II. / Composiciones dramáticas originales. /"; p. [1] 4-427 texto; [1] 429445 Ensayo biográfico firmado al fin por "José"; [2] índice. $4^{\circ}$ $200 \times 125 \mathrm{~mm}$.

Reimpresión de la primera edición. En la sección número 4, abajo, se hallará una tentativa de precisar la fecha y el lugar de la primera aparición de cada poesía. De aquella lista no aparecen en estas colecciones los números $27,49,60,70 \mathrm{y}$ 76; en cambio, estas colecciones contienen de más los siguientes poemas:

¡Adiós! (Primera línea: El crudo destino me fuerza á no verte, /) s. f.

Epigramas. (Son dos y empiezan así: Mi afición ....; Uno oyendo...) s. $f$.

Al señor don José Joaquín Pesado. Fechado a 14 agosto 1837.

Un momento de furor. Fecha: 1837.

Oda leída en 30 de agosto de 1838 en la distribución de premios del Colegio de San Juan de Letrán.

¡Guerra á los Galos, guerra! / (primera línea, no hay título.) Fechado en 1839.

Por vez primera; á mi amigo Eulalio-María Ortega. Fechado a $1^{\circ}$ nov. 1840 .

Poesía (primera línea: Musa de la verdad, mi labio inspira: /) s. $f$.

La gloria y el amor. Fechado: 19 feb. 1842 .

La visión de Moctezuma, leyenda. Fechada a 3 marzo 1842.

La cazadora. Fechado: 5 marzo 1842.

La pescadora. Fechado: 7 marzo 1842.

Grecia asentada en su corcel soberbio / (primera línea, no hay título.) s. f.

La gota de rocío, á mi amigo M. Esteva y Ulíbarri. Fechado: 10 abril 1842 . 
Letrilla veracruzana. Fechado a 30 mayo 1842.

Amigo, ¿quieres que en la patria mía / (primera línea, no hay título.) Fechado en la Habana, 14 junio 1842.

La gota de hiel. Fechado en la Habana, a 18 junio 1842.

El poeta en el mundo, á Antonio Bachillex y Morales. Fechado en la Habana, 1842.

¡Oh tormento feroz! - Alárcos, llora, / (primera línea, no hay título.) Fechado en la Habana, junio 1842.

Alárcos infeliz, vano es tu ruego, / (primera línea, no hay título.) Fechado en la Habana, junio 1842.

Nulidad de la vida, imitación del Psalmo 89. s. f.

Inés de Castro. Acto Iv, escena 3. ('Traducido de la tragedia del mismo nombre, original del portugués Juan B. Gómez.)

Nuño Almazán, cuento mejicano del siglo xvir. Fechado a 12 mayo 1837.

Cercada de tinieblas / (primera línea, no hay título.)

-Paje, tu penar no cesa; / (primera línea no hay título.)

Yo he cargado de amor el duro yugo; / (primera línea, no hay título.)

La biografía firmada por "José" puede ser obra de José Maria Tornel, íntimo amigo y protector del poeta, al parecer publicada antes en el Museo mexicano - véase bajo "J." en nuestra sección 8.

Ejemplares: DLC, MxF, MxJ, TxU, ViU.

3. Poesías / de / Ignacio Rodriguez Galván / Tomo I / Composiciones líricas originales / raya / Veracruz-Puebla / Librerías / "La Ilustración" [3 líneas antecedentes todas a la izquierda; a la derecha de una raya vertical]: Paris / A. Donnamette / 81 , calle des Saints-Pères, $81 / / 1883 /$

Tomo 1\%: Anteportada: Biblioteca de autores mejicanos, v. bl.; portada, v. bl.; p. [1] v-xix. Algunos rasgos biográficos de Ignacio Rodríguez Galván, ligero examen de sus obras, firmado por Rafael de la Colina, en Puebla, feb. de 1881; 1-290 texto; [1] 292 índice, y al pie de esta última página: Corbeil. Imprenta Crété. / Tomo $2^{\circ}$ : Anteportada, v. bl.; portada con Tomo II / Composiciones dramáticas originales /", v. bl.; p. 1-345; texto [1] bl.; [1] índice con pie de imprenta; [1] bl.

Reimpresión de la segunda edición.

Ejemplares: DLC, IaU, CoDU, MxF, MxFI, MxFU, MxJ, NN, NRU, ViU. 


\section{OBRAS QUE EDITO}

4. El/año nuevo/de / 1837. / [pleca] / Presente amistoso. / [pleca] / Méjico. / Librería de Galván / Portal de Agustinos n 3. / Anteportada, v. bl.; portada, v.: Imprenta de Galván a cargo de Mariano Arévalo, / calle de Cadena n. 2. / ; p. [1] iv prólogo, sin firma; 5-188 texto; 189 El Editor; 190 índice. $149 \times 90 \mathrm{~mm}$.

Valioso anuario que sirvió de órgano a los jóvenes literatos de la Academia de San Juan de Letrán, durante los años 1837 a 1840. Casi todos los trabajos publicados eran originales y por lo tanto -figurando sus autores entre los más notables de la época- representan una contribución importante a las letras mexicanas. Los críticos de la literatura mexicana no desconocen estos volúmenes, pero muy pocos los han podido consultar a causa de su rareza. En ellos se publicaron algunos de los primeros ensayos del romanticismo mexicano, en poesías, dramas y novelas. De este primer tomo hay una reseña en el Mosaico mexicano, t. 1 (México, 1836), p. 339. Publicó un examen crítico y extenso de las composiciones el eminente crítico José Gómez de la Cortina (véase nuestra sección 8 , bajo este nombre).

Ejemplares: EM, MxF, TxU.

5. El / año nuevo/de/1838. / [pleca] / Presente amistoso. / [pleca] / Méjico. / [dos plecas] / En la librería de Galván, / Portal de Agustinos n. 3./

Anteportada litografiada, v. bl.; portada, v. con una cita de Malon de Chaide y: Imprenta de Galván a cargo de Mariano Arévalo, / calle de Cadena núm. 2. / ; p. [1] iv prólogo firmado por "Los editores"; $5-255$ texto; 256 índice. $149 \times 90 \mathrm{~mm}$.

Aunque no consta en ninguno de los tomos quién era el editor, tenemos la afirmación del hermano del autor en la biografía que escribió para la primera edición de las poesías, a más de la de dos contemporáneos de Rodríguez Galván, que lo era él. Consúltense el Año nuevo, presente amistoso (México, 1848), editado por Manuel Payno, p. [i] y Guillermo Prieto, Memorias (México, 1906), t. 1, p. 217. Las composiciones del editor las detallamos bajo nuestras secciones correspondientes.

Ejemplares: EM, MxF, TxU.

6. El / año nuevo / de / 1839. / [pleca] / Presente amistoso. / [pleca] / Méjico. / [pleca] / En la librería de Galván, / Portal de Agustinos n. 3./ 
Portada, v.; Imprenta de Galván a cargo de Mariano Arévalo, '/ calle de Cadena núm. 2./; p. [2] prólogo, sin firma; 5-215 texto; [1] índice. $150 \times 92 \mathrm{~mm}$.

Ejemplares: EM, $\mathrm{MxF}$.

7. El/año nuevo/de 1840./[pleca]/Presente amistoso./[orn.]/ Mégico. / En la librería de Galván, portal de Agustinos n. 3./

Anteportada o forro litografiado, v. bl.; portada, v.: Imprenta de Galván, dirigida por $M$. Arévalo, / calle de Cadena n. 2. / ; p. [1] iv-v prólogo; [1] bl.; 7-265 texto; [1] bl.; 267-268 índice. $154 \times 93 \mathrm{~mm}$.

Creo que se debe la cesión de tan interesante periódico a la falta de protección del literato e impresor don Mariano Galván Rivera, tío del poeta. Durante el año 1840 tuvo un pleito que al fin perdió $y$, con él, su imprenta. Su sobrino, según parece, se separó de la librería de Galván, donde sirvió de dependiente, y acudió al entonces Ministro de Guerra, José María Tornel, quien "creó una plaza de escribiente supernumerario para que Rodríguez Galván no muriera de hambre" (Olavarría y Ferrari). Véanse también el Calendario de las señoritas megicanas, para el año de 1843 , dispuesto por Mariano Galván, p. [5]-6, y Colección de las efemérides publicadas en el Calendario del más antiguo Galván (México, 1926), p. 6-7.

Ejemplares: EM, MxF.

8. Calendario / de las/señoritas megicanas/para el año 1838 , / dispuesto / por Mariano Galván. / [orn.] / Mégico, / en la librería del editor, / Portal de Agustinos, 3./

Anteportada, v.: Paris. - A. Everat; hoja para dedicatoria litografiada en el recto, v. bl.; portada, v. bl.; p. [1] 6-7 El Editor; [1] bl.; [1] 10-60 calendario; [1] 62-317 parte literaria; [6] 323 sobre modas; [1] $326-327$ índice; [1] bl. $124 \times 78 \mathrm{~mm}$. 10 láminas, 3 en colores.

Primero de los cinco calendarios literarios que editó el impresor Mariano Galván. Aunque ninguno de los biógrafos del poeta le atribuye la labor editorial de estos calendarios, me parece muy probable que haya ayudado a su tío en la confección de ellos. El tipo de composiciones románticas y el hecho de que salieron algunas obras suyas, con su firma, en el último calendario después de su muerte, todo parece sugerir que el poeta no sólo intervino en la compilación, sino que también era autor de algunas de las composiciones anó- 
nimas de los primeros calendarios. Ofrezco en prueba de esta atribución el caso del cuento histórico $E l$ visitador, que apareció en el calendario de 1838. No hay indicación alguna del autor pero el mismo cuento salió poco después en el Museo yucateco, t. 1, p. 348-56, bajo la firma de Ignacio Rodríguez. Como así firmaba a veces el poeta, y como la reedición del cuento apareció en el Museo en 1841, cuando todavía vivía Rodríguez Galván, parece no haber duda alguna de que en en efecto era éste el autor. Tampoco es mera coincidencia que el personaje principal del cuento fuese el visitador Muñoz, de quien Rodríguez trata en su drama Muñoz, visitador de Méjico (1838). Las otras composiciones que parecen ser del poeta, las pongo en lista en las secciones correspondientes.

Ejemplares: DLC, EM, ICN, LNT, NN.

9. Calendario / de las / señoritas megicanas, / para el año 1839,/dispuesto / por Mariano Galván. / [orn.] / Mégico, / en la librería del editor, / Portal de Agustinos, $\mathbf{n}^{\circ}$ 3./

Anteportada, v.: New-York; hoja con dibujo en dos colores, v. bl.; portada, v. bl.; p. [1] 6-8 El Editor; [1] 10-50 calendario; [1] 52-311 parte literaria; [1] bl.; [1] 314-316 [8] sobre modas; [1] 326-343 nombres propios y días de santo; [1] bl.; [1] 346 índice, $124 \times 78 \mathrm{~mm}$. Hay 10 láminas, 5 en colores.

Ejemplares: EM, NN.

10 Calendario / de las / señoritas megicanas, / para el / año bisiesto de 1840, / dispuesto / por Mariano Galván. / [orn.] / Mégico, / en la librería del editor, / Portal de Agustinos, $n^{\circ}$ 3./

Anteportada, v.: Paris. - Decourchant, donde se imprimió; hoja con dibujo a dos colores, v. bl.; portada, v. bl.; p. [2] dedicatoria, v. bl.; [1] 8-48 calendario; [1] 50-308 parte literaria; [6] modas; [1] 316-334 nombres propios y dias de santo; [1]

336 índice. $125 \times 80 \mathrm{~mm}$. 10 láminas, 3 de ellas en colores.

Ejemplar: EM.

11. Calendario / de las / señoritas megicanas, / para el año 1841, / dispuesto / por Mariano Galván. / [orn.] / Mégico, / en la librería del editor, / Portal de Agustinos, $\mathrm{n}^{\circ} 3$. /

Hoja con dibujo a dos colores, v. bl.; portada, v. bl.; p. [1] 6 prólogo, firmado por Mariano Galván Rivera; [1] 8-50 calendario; [1] 52-332 parte literaria; [1] 334-339 [7] modas; [1] 348 índice. $120 \times 85 \mathrm{~mm}$. 10 láms., 3 de ellas en colores. 
Como falta la anteportada en mi ejemplar, no se puede decir dónde se imprimió.

\section{Ejemplar: EM.}

12. Calendario/de las/señoritas megicanas, / para el año de 1843,/ dispuesto / por Mariano Galván. / [orn.] / Mégico, / en la librería del editor. / Portal de Agustinos, $n^{\circ}$ 3./

Anteportada, v. bl.; hoja con dibujo a dos colores, v. bl.; portada, v. bl.; p. [1] 6 Señoritas megicanas, prólogo; [1] 8-50 calendario; [1] 52-304 parte literaria; [1] 306-310 [8] modas; [1] 320 índice. $120 \times 85 \mathrm{~mm}$. 9 láminas, 4 de ellas en colores.

Ultimo de la serie. Galván, explicando en el prólogo que suspendió este calendario en el año anterior "por los memorables sucesos del infando de 41", indica que en aquel año sufrió grandes pérdidas personales. Sin embargo, se anima a publicar éste de 43 "para ver si merece de vosotras una acogida más eficaz" que la que recibió en 41. Agrega que "vosotras en parte habéis contribuído á su desgracia, por no comprar todas el Calendario". Parece que la acogida no compensaba el gran esfuerzo del editor, que produjo en esta serie de calendarios tal vez las más bellas obras mexicanas de aquella época. A pesar de ser impresos todos al parecer en París, el Calendario puede considerarse mexicano por representar el saber tipográfico del editor y por contener muchas composiciones de autores mexicanos. "Despertaron la emulación de los impresores de alcurnia y ... sin duda a ellas se deben los alardes editoriales que se hicieron en México al entrar los años cuarentas" - Enrique Fernández Ledesma, Historia crítica de la tipografía en la ciudad de México (México, 1935), p. 62. No menos de diez composiciones de Ignacio Rodríguez Galván se publicaron en este último tomo del Calendario. $\mathrm{O}$ quiere decir que su tío le dedica el tomo a su muerte, que ocurrió a mediados del año 1842, o que la participación del poeta como autor, aunque anónimo, de las composiciones en los tomos anteriores, era en efecto muy importante. Las fechas al calce de las poesías corren desde 1839 hasta enero de 1842. No sería imposible que tuviese parte en esta compilación nuestro poeta, porque en aquellos días sería necesario preparar la copia con casi un año de anticipación para mandarla a París y recibir a fines de 1842 la obra impresa.

Ejemplar: EM.

13. E1/recreo/de las familias. /...est bien fou du cerveau / qui prétend contenter tout le monde.../ La Fontaine. / [orn. con 
las palabras "En un volúmen"] / Mégico: / Librería de Galván. / [pleca] / 1838./

Portada, v.: Impreso por Mariano Arévalo, / calle de Cadena núm. 2. /; p. [2] prólogo, sin firma; 5-472 texto; 473-475 anuncia la cesión del periódico; 476-478 indice; $479-482$ lista de suscritores. $225 \times 145 \mathrm{~mm}$. ilustrado.

Cesó la publicación por falta de suscritores. No lo hace constar así el redactor, pero lo descubre el hermano del poeta en su biografía y lo afirma también un compañero de Rodríguez Galván en la que a su vez le dedicó en el Diccionario universal de historia y de geografía, t. 6 (México, 1855), p. 64448, suscrita por E. M. O., o sea Eulalio Maria Ortega. De esta revista habla nuestro docto y modesto amigo Jefferson R. Spell en su utilísimo artículo "Mexican literary periodicals of the nineteenth century", PMLA, t. 52, núm. 1, p. 304305 , en los siguientes términos: "Less nationalistic in scope is El Recreo de las Familias, which includes, with original contributions by native literati, material from contemporary foreign literary journals, chiefly from the celebrated journal of the Spanish Romantic school, El Artista, edited by Eugenio Ochoa, who was also its most voluminous contributor. Of his articles, El Recreo reprinted 'Ramiro,' a Romantic tale; biographical sketches on Velásquez, Gallego, Trueba de Cossío, Murillo, Quintana, and Lope de Vega; an essay entitled 'Literatura'; and the poem 'Un suspiro de amor.' Other material from El Artista includes selections from García Gutiérrez's El Trovador; Trueba de Cossio's translation 'Sitio de Corinto,' by Byron; and Espronceda's 'Canción del Pirata' and excerpts from his 'Pelayo.' That this Spanish periodical furnished both inspiration ad literary models to the young Mexican contributors to El Recreo is clear; for not only did the biographical sketches and articles on literature by Ochoa suggest similar ones to the Mexican editors, but the influence of certain poems first printed in it - for example, Espronceda's 'Canción del Pirata' on Fernando Calderón's 'El soldado de la libertad' - is at once apparent. The Romantic spirit shows itself, too, in the melancholy nature of Rodríguez Galván's poems, such as 'La tumba,' and in both his and Sánchez de Tagle's translations from Lamartine. Though .the influence of Romanticism is marked in the periodical as a whole, Classicism is not without its adherents, for Pesado published in it some of his finest poems." Parece mentira que ningún critico se haya fijado todavía, al tratar de la obra de Rodríguez Galván, en lo mucho que influyeron en la formación de sus gustos literarios las tareas editoriales del Recreo. Un año des- 
pués habla el poeta en su propia defensa y nos revela que se ha aprovechado de las traducciones que sigue haciendo: "Muchos notarán que hai en ella - se refiere al Año nuevo de 1840 ; véase p. iv- varios artículos traducidos, lo que arguye poca originalidad. A eso dirémos, que siempre que lo que se traduzca sea en sí bueno, no hai en ello desventaja, sinó que por el contrario es útil, i prueba que las obras estrangeras dignas de aprecio, son conocidas entre nosotros, i nos agradan. No hai quizá una nación que no haya dado principio a su literatura traduciendo lo bueno que hai en las estrañas. Sucede a los que se dedican a las bellas letras lo que a los pintores, quienes tienen que copiar mucho ántes de ser inventores." Muchos de los artículos anónimos que se publican en el Recreo posiblemente son del poeta; las composiciones que seguramente le pertenecen las dejamos anotadas en otras secciones de esta bibliografía.

Ejemplares: MxMi, MxZ.

14. El teatro escogido.

Antonio Rodríguez Galván, en la biografía ya citada, menciona ésta como obra publicada por el poeta. ¿Sería una colección de piezas de autores nacionales y extranjeros? No he podido encontrar ninguna obra con este título en las muchas bibliografías mexicanas que he consultado. Tampoco pude hallarla en algunas de las bibliotecas principales de México. No puedo creer que se haya equivocado el hermano del autor en cuanto a la existencia de esta obra, y así, espero que algún día aparezca un ejemplar de tan raro libro.

\section{OBRAS DRAMATICAS}

15. La capilla, escena dramática. El año nuevo, 1838, p. 51-63.

Firmada: I. Rodríguez. Fechada: 6 agosto 1837. Jamás se representó. En cuatro partes y en prosa.

16. Muñoz, / visitador de Méjico. / Drama / en tres jornadas y en verso, / por / Ignacio Rodríguez. / Representado por primera vez en el Teatro Princi-/ pal de Méjico, la noche del 27 de setiembre de 1838. / [cita de Lope de Vega de 4 líneas] / Méjico: 1838./ [raya] / Librería de Galván, / Portal de Agustinos N. 3./

Portada, v.: Impreso por Mariano Arévalo, c. de Cadena N. 2. / ; 7 hojas prls., [2] 3-130 p., 1 hoja. $165 \mathrm{~mm}$.

Se representó otra vez durante la vida del autor, el 29 de junio de 1841 , sin lograr más que un éxito mediano. Véanse 
Manuel Mañón, Historia del Teatro Principal de México. (México, 1932), p. 84, y en la sección 8, bajo "Teatro Principal".

Ejemplares: $\mathrm{Cu}-\mathrm{B}, \mathrm{NN}$.

17. Muñoz, visitador de México, fragmento. En la Biblioteca del estudiante universitario / 30 / Poesía / romántica / Prólogo de / José Luis Martínez / Selección de / Alí Chumacero / Ediciones de la Universidad nacional autónoma / México 1941/

[1] hoja prl., p. xxv, [1], 203, [2]. Las siete composiciones del poeta ocupan las páginas 21 a 55 , y son: Mi ensueño; Una flor; A la muerte; Adiós, oh patria mía; Suspende el rápido vuelo;

Muñoz, y Profecía de Guatimoc.

18. El precito. Drama que no se publicó, según parece. La noticia más clara y extensa que tenemos nos la da Guillermo Prieto en sus Memorias, t. 1, p. 130: "Ensayó también un drama que se titulaba el Precito, en que ángeles y demonios, monstruos y vestiglos, frailes $\mathrm{y}$ chinas, reyes y mendigos andaban á las vueltas, y en que los trancos, no actos, abarcaban infierno, cielo y tierra en desastrada confusión." Sería el primer ensayo dramático del autor, del que no nos ha llegado: ningún ejemplar.

19. El privado del virrey. Drama en cinco jornadas. México, Impreso por Ignacio Cumplido, 1842.

159 p. $200 \mathrm{~mm}$.

Tomamos la descripción de la obra citada de Francisco Monterde, p. 308. Se estrenó el 24 de abril de 1842 en el Teatro Principal de México, según Olavarría y Ferrari, Teatro, t. 2, p. 47, y Mañón, obra citada, p. 88 , aunque no nos dicen cómo la recibió el público.

Ejemplares: $\mathrm{Cu}-\mathrm{B}, \mathrm{MxFI}$.

20. La señorita. Fragmento de El Angel de la Guarda, comedia inédita. En el Calendario de las señoritas megicanas, 1843 , p. 51-56.

Lleva la fecha 1839 y el nombre del autor al fin. En verso.

21. El teatro moderno. Fragmento de El Angel de la Guarda, comedia inédita. En el Calendario, 1843, p. 289-291.

4. POESIAS

22. A don Miguel Mata y Reyes. Repertorio de literatura y variedades (México, 1841), p. 205-206.

Fechada a 7 dic., 1840 y firmada por el autor. 
23. A ella. El año nuevo, $183 \dot{7}$, p. 116.

Fechada: 18 dic., 1836. Firmada: I. R. G.

24. A la muerte de mi amigo d. Antonio Larrañaga. En Año muevo, 1939, p. 157-160.

Fechada: 17 dic. 1838. Firmada: I. Rodríguez.

25. Idem. Véase nuestro número 17.

26. A la niña Rosa Galván Rodríguez. Calendario de las señoritas megicanas, 1843, p. 97-102.

Fechada: 23 marzo 1840. Firmada: I. R. Galván.

27. A un jóven. Recreo de las familias, p. 334.

Anónima.

28. Adiós joh patria mía! Guirnalda poética. / [pleca]/ Selecta colección / de poesías mejicanas. / [orn.] / Publicada / por Juan R. Navarro / para obsequiar á los señores suscritores á la / Biblioteca nacional y extranjera. / [orn.] / Méjico. / [pleca] / Imprenta de Juan R. Navarro, calle de Chiquis n. 6./[pleca] / 1853./

Portada, v. bl.; p. [2] A1 que leyere; [2] suscritores; [1] 8-293 [1] texto; [2] índice, firmado por Juan R. Navarro, sin duda el editor.

La poesía de Rodríguez Galván se halla en las páginas 259. 262. Damos arriba la descripción bibiográfica completa de esta antología, porque todavía no se ha descrito por bibliógrafo mexicano alguno.

29. Adiós ¡oh patria mía! Véase nuestro número 17.

30. Al buitre. Se publicó por primera vez en un periódico veracruzano bajo el seudónimo "Isidoro de Almada" - Guillermo Prieto, Memorias, t. 1, p. 130.

Es una de sus primeras y peores poesías románticas. También se publicó bajo el nombre "El canto de venganza".

31. Amor. A una niña de seis años de edad. Calendario de las señoritas megicanas, 1843, p. 103-107.

Fechada: 16 sep. 1841. Firmada: I. R. Galván.

32. El anciano i el mancebo. Año nuevo, 1840, p. 234-243. Fechada: 29 dic. 1839. Firmada: I. Rodríguez.

33. Idem. Antología/de/poetas mexicanos/publicada/por la Academia mexicana/correspondiente de la Real española./[Pleca] / 
Segunda edición. / [pleca] / México / Oficina tip. de la Secretaría de fomento / calle de San Andrés núm. 15. (Avenida Oriente 51.) / [pleca] / $1894 /$

P. [5], vi; [1] 2-56 Reseña histórica de la poesía mexicana, firmada por J[osé] M[aría] Vigil; [3] 60-488 texto; [1] ii-iii índice; [1].

La poesía del poeta ocupa las p. 140-148 y va acompañada de las fechas vitalicias de él.

34. Idem. México poético/colección de/poesías escogidas de autores mexicanos / formada / por Adalberto A. Esteva / [orn.] / México / Tipografía de la oficina impresora del timbre/Palacio nacional/ $1900 /$

[5] $2-180 ;[6]$.

La poesía en las p. $26-37$.

35. Idem. Véase nuestra sección $8^{a}$, bajo "Holmes".

36. El ángel caído. Año nuevo, 1840, p. 119-128.

Fechada: abr. 1839. Firmada: I. Rodríguez.

37. ¡Bailad! ¡Bailad! El Mosaico mexicano (México, 1841), p. 326.

Firmada: Jeconias, pero es de Rodríguez Galván. Fué publicada antes en El Cosmopolita.

38. Idem. El parnaso mexicano. / [pleca] / Ignacio Rodríguez Galván. / Su retrato y biografia / con el juicio critico de sus obras / y / poesias escogidas de varios autores/coleccionadas/bajo la dirección del sr. / gral. d. Vicente Riva Palacio, [8 líneas]/[pleca]/Libreria La Ilustracion. / 12. - primera de Santo Domingo.- 12 / [pleca] / México, $1^{\circ}$ de agosto de $1885 . /$

Anteportada, v. bl.; retrato litografiado; portada, v. bl.; p. [1] 6-9 Apuntes biográficos por Ignacio M. Altamirano; [1] bl.; 1113 Bailad! Bailad!; $14-96$ poemas de otros autores nacionales. $136 \times 158 \mathrm{~mm}$.

Sólo contiene una poesía de Rodríguez Galván.

38 bis. El Buitre. Véase número 30.

39. Cántico al Señor. Imitación del Salmo 135. Calendario de las señoritas megicanas, 1843, p. 225-228.

Fechado: sep. 1841. Firmado: I. R. Galván. 
40. El canto de venganza. El Mosaico mexicano, t. 1 (México, 1836), p. 493-495.

Véase nuestro número 30.

41. El ciego. El Recreo de las familias, p. 446-447.

Fechada: 12 marzo 1838. Firmada: I. R.

42. Idem. El Espectador de México, t. 4 (México, 1851), p. 54-58.

Firmado: Ignacio Rodríguez Galván.

43. Un crimen. Año nuevo, 1838, p. 158-62.

Fechada: 13 oct. 1837. Firmada: I. Rodríguez.

44. El desengaño. El Diorama (México, 1837), p. 63-64.

Fechada: 24 feb. 1837. Firmada: I. R.

45. Idem. Repertorio de literatura y variedades, t. 2 (México, 1842), p. 78-79.

Firmada: I. R.

46. Eva ante el cadáver de Abel. El Museo popular (México, 1840), p. 211-213.

Fechada: 23 mayo 1837. Firmada: I. Rodríguez.

47. Una flor. Año nuevo, 1840, p. 129-30.

Fechada: 15 feb. 1839. Firmada: I. Rodríguez.

48. Idem. Véase nuestro número 17.

49. ¡Gran Dios, qué divina! El Mosaico mexicano, t. 2 (México, 1837), p. 300 .

Firmada: Ignacio Rodriguez.

50. $\mathrm{El}$ infortunio. Año nuevo, 1838, p. 77-79.

Fechada: 21 abr. 1837. Firmada: I. Rodríguez.

51. La inocencia. Año nuevo, 1839 , p. 83-88.

Fechada: 27 jun. 1838. Firmada: I. Rodríguez.

52. El insurgente de Ulúa. Año nuevo, 1837, p. 57-60.

Fechada: 19 nov. 1836. Firmada: I. R. G.

53. Jalapa. El Mosaico mexicano, t. 7 (México, 1842), p. 566.

Fechada: 23 mayo 1842. Firmada: Ignacio R. Galván.

54. El licenciado Muñoz. El Diorama (México, 1837), p. 80.

Fechada: 24 abr. 1837. Firmada: I. Rodríguez. 
55. Mi ensueño. Año nuevo, 1839 , p. 104.

Fechada: 19 dic. 1838. Firmada: I. Rodríguez.

56. Idem. Sonetos varios/de la / musa mexicana. / Colección dedica$\mathrm{da} / \mathrm{al}$ insigne poeta español/d. José Zorrilla. / [pleca] / México. / [pleca]/Imprenta de Vicente Segura, / calle de Cadena núm. 10. / [pleca] / 1855./

Anteportada, v. bl.; portada, v. bl.; [1] 6-218 texto; [2] índice; [4] bl. Obra editada anónimamente por José Sebastián Segura, que contiene poemas de veintitrés poetas mexicanos.

La poesía de Galván se halla en la p. 33.

57. Idem. Véase nuestro número 17.

58. Mis ilusiones. Año nuevo, 1839 , p. 95-100.

Fechada: 6 sep. 1838. Firmada: I. Rodríguez.

59. Mora. Año nuevo, 1837, p. 117-141.

Fechada: 10 sep. 1835 . Firmada: I. R. G.

60. La muger. El Recreo de las familias, p. 125.

Sin firma, pero creo que es obra de Galván.

61. El Pájaro. Año nuevo, 1837, p. 54-57.

Fechada: 15 abr. 1835. Firmada: I. R. G.

62. El perro egoísta. Fábula. Calendario de las señoritas megicanas, 1843, p. 165-169.

Fechada: 1841. Firmada: I. R. Galván.

63. La poesía, el amor y el licor. Año nuevo, 1839, p. 101-103.

Fechada: 10 jun. 1838. Firmada: I. Rodriguez.

64. Profecía de Guatimoc. Año nuevo, 1840, p. 60-76.

Fechada: 16-27 sep. 1839. Firmada: I. Rodríguez.

65. Idem. Véase nuestra sección $8^{\text {a }}$, bajo "Menéndez y Pelayo".

66. Idem. Las cien mejores poesías (líricas) mexicanas. Nueva edición refundida. México, Librería de Porrúa hnos. y cía., 1935.

[4] h. prls., p. [1] viii- $x x x, 284,[4]$. Hay otra edición de 1914.

La poesía del poeta en las p. 105-120.

67. Idem. Véase nuestro número 17. 
68. Un rayo de la luna. El Recreo de las familias, p. 285.

Firmada: I. Rodríguez. Fechada a 30 enero 1838.

69. La sanguijuela i el cerdo. Fábula. Año nuevo, 1840, p. 179-181. Fechada: 9 marzo 1839. Firmada: I. Rodríguez.

70. La satisfacción. El Recreo de las familias, p. 297. Anónima, pero ¿poesía de Galván?

71. El soldado ausente. El Recreo de las familias, p. 439-440.

Fechada: 15 marzo 1838. Firmada: I. Rodríguez.

72. El sordo en el concierto. Año nuevo, 1839, p. 32-35.

Fechada: 19 dic. 1838. Firmada: I. Rodríguez.

73. Suspende el rápido vuelo. Semanario de las señoritas mejicanas, t. 3 (México, 1842), p. 377-378.

Fechada: 1837. Firmada: I. Rodríguez Galván.

74. Idem. Véase número 17.

75. El tenebrario. El Mosaico mexicano, t. 2 (México, 1837), p. 160. Firmado: Ignacio Rodríguez.

76. El tocado. Repertorio de literatura y variedades, t. 1 (México, 1841), p. 121-122.

Firmado: I. Rodríguez. En prosa y verso.

77. La tumba. El Recreo de las familias, p. 107, 126-131, 168-175, 256269.

\section{NOVELAS Y CUENTOS}

78. La cruz rústica. Calendario de las señoritas megicanas, 1839, p. 85124.

Anónima, pero la creo obra de Galván.

79. Idem. Biblioteca de autores mexicanos, 33. Novelas cortas de varios autores. Tomo I. México, Imp. de V. Agüeros, 1901, p. 435.465.

También anónima.

80. Don Juan de Escobar. Calendario de las señoritas megicanas, 1838, p. 67-100.

Anónima, pero probablemente obra de Galván.

81. Idem. En la Biblioteca de autores mexicanos citada arriba, p. 385 412. 
82. La hija del oidor. Año nuevo, 1837, p. 73-94.

Fechada: 27 nov. 1836. Firmada: I. R. G.

83. Idem. En la Biblioteca de autores mexicanos citada arriba, p. 91-114.

84. Manolito el pisaverde. Año nuevo, 1838, p. 163-199.

Fechada: 9 nov. 1837. Firmada: I. Rodríguez.

85. Idem. En la Biblioteca de autores mexicanos ya citada, p. 115-156, bajo su nombre.

86. La procesión. Año nuevo, 1839, p. 105-156.

Fechada: dic. 1838. Firmada: I. Rodríguez.

87. Idem. También en el vol. 33 de la Biblioteca de autores mexicanos, p. 157-212, bajo su nombre.

88. Ricardo y Laura. Calendario de las señoritas megicanas, 1843. p. 171198.

Lleva al fin la inicial "G", que puede ser de Mariano Galván, de Ignacio Gondra o de nuestro poeta.

89. Idem. Biblioteca de autores mexicanos, t. 33, p. 467-488, anónima.

90. Tras un mal nos vienen ciento. Año nuevo, 1840, p. 133-178.

Firmado: I. Rodríguez. Cuento dialogado.

91. Idem. Biblioteca de autores mexicanos, t. 33, p. 213-262.

92. E1 visitador, Año de 1567. Calendario de las señoritas megicanas, 1838, p. $265-292$.

Anónima, pero de Rodríguez Galván. Véase número 8.

93. Idem. El Museo yucateco (Mérida, 1841), t. 1, p. 348-356.

Firmado: Ignacio Rodríguez.

94. Idem. Biblioteca de autores mexicanos, t. 33, p. 413-433, anónimo.

95. El zapatero literario. El Recreo de las familias, p. 385-386.

Cuento corto.

\section{ARTICULOS VARIOS}

96. Bretón de los Herreros. El Recreo de las familias, p. 441-445. Biografía y crítica, con retrato litografiado. 
97. Calderón. Ibidem, p. 2-12.

Firmado: R. Fragmentos y crítica.

98. Un coplero mejicano del siglo XIX. Año nuevo, 1838, p. 147-157. Firmado: R. Artículo costumbrista. Fecha: 19 oct. 1837.

99. Don Angel de Saavedra. El Recreo de las familias, p. 361-370. Biografía y crítica con retrato litografiado.

100. Doña Concepción Domínguez. Ibidem, p. 457-459.

Biografía, con retrato litografiado. Firmado: I. R.

101. Leyendas españolas por José Joaquín de Mora. Repertorio de literatura y variedades, t. 1 (México, 1841), p. 209-212.

Reseña crítica.

\section{TRADUCCIONES}

102. El ángel y el niño, elegía a una madre, traducida de Juan Reboul. Calendario de las señoritas megicanas, 1843, p. 199-202.

Fechada: 30 mayo 1841. Firmada: I. R. Galván.

103. Antigüedades. El Mosaico mexicano, t. 2 (México, 1837), p. 180184.

Las iniciales I. R. G. que calzan el artículo pueden ser también de Ignacio Rafael Gondra. El original es de Julia Fontenelle.

104. Artes y oficios. Ibidem, p. 394-398.

Firmado: I. R. G. Véase nota número 103.

105. Bellas artes. El Recreo de las familias, p. 55-62, 132-137.

Traducido del Enciclopedie por I. R. G.

106. Catalina Howard, drama de Alejandro Dumas. Citando un dato de Ignacio M. Altamirano, Francisco Monterde, en su Bibliografía del teatro en México, p. 476, atribuye esta traducción a nuestro autor. Consultando El Apuntador (México, 1841), vemos que el 28 de agosto de 1841 se representó dicho drama en el Teatro Principal, con Soledad Cordero en el papel sobresaliente. Aunque hubo otras. representaciones de Catalina Howard, creo que si Rodríguez Galván hizo una traducción es muy probable, dado su amor a la citada actriz, que sea ésta, la que ella representó.

Es casi seguro que no llegó a imprimirse.

107. La confesión de Luis XI, fragmento. Año nuevo, 1840, p. 245-260. Traducción libre de la tragedia Luis XI, de Casimiro Delavigne, acto IV, escenas 6 y 7 . Firmado: I. Rodríguez. 
108. Las desgracias de Kan, tragedia histórica de los chinos. El Recreo de las familias, p. 194-199.

Original de Han Kong Tsew. Traducida del francés por I. Rodríguez.

109. Espejo de los poetas, epigrama. Calendario de las señoritas megicanas, 1843 , p. 137.

Original de Balochi.

110. Genoveve de Brabante, tragedia. El Recreo de las familias, p. 427435.

Traducción de un extracto hecho por X. Marmier. Firmado: I. Rodríguez.

111. La guerra civil. Año nuevo, 1840, p. 182-187.

Imitación de $E l$ conde de Carmañola, acto II, coro, de Alejandro

Manzoni. Firmado por I. Rodriguez y fechado a 19 ago. 1839.

112. El incendio, por Dupaty. El Recreo de las familias, p. 53-54.

Traducción firmada por R. Prosa histórica.

113. La isla desierta, drama del abate Metastasio. Calendario de las señoritas megicanas, 1838, p. 191-218.

Traducción anónima, pero posiblemente de Galván.

114. Los mundos imaginarios, por Aimé Martin. Ibidem, 1843, p. 229256.

Traducción firmada: I. R. Galván. Novela.

115. La pasión, himno sagrado traducido de Alejandro Manzoni. Ibidem, p. 131-136.

Fechado: enero 1842. Firmado: I. R. Galván.

116. Razas americanas. El Mosaico mexicano, t. 2 (México, 1837), p. 200 .

Las iniciales al fin, I. R. G., pueden ser de Isidro Rafael Gondra o de nuestro poeta y traductor.

117. Siroe, rey de Persia, ópera del abate Metastasio. Calendario de las señoritas megicanas, 1839 , p. 163-255.

Traducción anónima. Monterde, obra citada, p. 477, trae la siguiente nota de Ignacio M. Altamirano: "Hay razones para creer que la traducción de esta pieza de Metastasio, que apareció anónima, pertenece a Galván.” No expresa Monterde dónde hace constar esto Altamirano y no he podido encontrar el pasaje. Nuestras razones para creerla de Galván, se expresan bajo nuestro número 8. 
118. La sombra de Dirce, fragmento. Año nuevo, 1840, p. 131-132.

Traducción del Aristodemo, acto II, escena 7, de Vicente Monti.

Firmada: I. Rodríguez.

8. OBRAS CRITICAS Y BIOGRAFICAS REFERENTES A GALVAN

Agüeros, Victoriano

Rodríguez Galván. El Tiempo Literario (México, 1883), p. 198201.

Estudio bien pensado, crítica justa, con amplio acopio de datos.

Altamirano, Ignacio Manuel

Ignacio Rodríguez Galván, Apuntes biográficos. Véase número 38.

Ignacio Rodríguez Galván. La Revista de México, t. 3, núm. 24 (16 junio 1889), p. 298-299.

Altamirano, Alberto I.

Influence de la littérature française sur la littérature mexicaine (México, s. f.), p. 39-40.

Busca la influencia de Alfred de Vigny, sin éxito.

Arróniz, Marcos

Manual de biografia mejicana (París, 1857), p. 277-280.

Breve biografía y apreciación, valiosas por ser obra de un contemporáneó del poeta.

Baz, Gustavo

Rodríguez Galván, ensayo crítico. El Domingo (México), $3^{2}$ época, núm. 2 (26 mayo 1872), p. 18-19.

Cejador y Frauca, Julio

Historia de la lengua y literatura castellana, t. 7. (Madrid, 1917), p. 214.

Copia a Menéndez y Pelayo, q. v.

Coester, Alfred

The literary bistory of Spanish America (Nueva York, 1928), p. 335-337.

Analiza las obras más conocidas de Galván.

Fernández Ledesma, Enrique

Viajes al siglo XIX (México, 1933), p. 63-69.

Trata de la boga de la actriz Soledad Cordero, de quien

Galván se había enamorado desatentadamente. 
Galán, E1 [seudónimo]

Teatro Principal, Catalina Howard. El Apuntador (México, 1841), p. 206-207.

Sobre la representación de este drama de Alejandro Dumas, tal vez traducción de Galván, el 28 ago. 1841.

Galindo, Miguel

Apuntes para la bistoria de la literatura mejicana (Colima, Colima, 1925), p. 154-158, 195.

Breve biografía con notas críticas.

García, Rubén

Rodríguez Galván, Ignacio. Fichas bio-bibliográficas mexicanas, serie II, núm. 8.

Breve resumen de su vida y obra; retrato.

García Cubas, Antonio

Diccionario geográfico, bistórico y biográfico de los Estados Unidos Mexicanos (México, 1890), t. 4, p. 459-460.

Artículo biográfico suscrito por $\mathrm{F}$ [rancisco] Sosa, tomado de su Mexicanos distinguidos, q. v.

Gómez de la Cortina, José Justo

Ecsamen critico / de / algunas / de las / piezas literarias/contenidas / en el libro intitulado / E1 / Año nuevo. / [pleca] / México. / [pleca]/Impreso por Ignacio Cumplido, / calle de los Rebeldes $n$. 2. / [pleca] / 1837./

Portada, v. bl.; p. [2] "Al sr. d. J. F. de L." firmado por el autor; 5-42 texto con firma al fin. $195 \times 120 \mathrm{~mm}$.

Con el propósito de alentar y corregir los esfuerzos creadores de los jóvenes literatos, este crítico diplomático e inteligente examinó una por una las composiciones del primer tomo del Año nuevo, haciendo observaciones muy atinadas para su corrección. Es una obra sumamente rara.

Ejemplares: C-S, TxU.

González Obregón, Luis

Breve noticia / de los / novelistas mexicanos / en el siglo XIX / por / Luis González Obregón. / [dos plecas] / México. / [pleca] / Típ. de O. R. Spíndola y Comp., Ex-Seminario 2. / 1889./

Portada, v. bl.; p. [2] dedicatoria, v. bl.; [1] 6-11 prólogo; [1] bl.; [1] 14-61 texto cronológico con 90 autores; [1] bl.; [2] índice. $134 \times 100 \mathrm{~mm}$.

Sólo menciona cuatro títulos del autor. 
González Peña, Carlos

Historia de la literatura mexicana (México, 1928), p. 306-309, $331-332$.

Crítica independiente y amplia. Véase también la $2^{\mathrm{a}}$ edición de la misma historia, que es idéntica, México, 1940, p. $169-$ 170,183 .

Holmes, Henry A.

Spanish America in song and story (Nueva York, 1932), p. 350353.

Reproduce "El anciano y el mancebo", con una brevísima indicación crítica.

Horta, Aurelio

Mexicanos ilustres; bosquejos biográficos para el uso de los establecimientos de instrucción pública (México, 1883), p. 73-76. Datos biográficos esenciales, con una nota sobre la actitud de Galván frente a la muerte.

$\mathrm{J}$.

Recuerdos biográficos, D. Ignacio Rodríguez Galyán. El Museo mexicano, t. 2. (México, 1843), p. 265-269.

Datos biográficos importantes. ¿Obra de José María Tornel, íntimo amigo y protector de Galván? Retrato litografiado.

Jiménez Rueda, Julio

Historia de la literatura mexicana (México, 1934), p. 150-151. $2^{a}$ edición. La $3^{\text {a }}$ es de México, 1942; véanse p. 149-150. Sigue en su crítica al señor Menéndez y Pelayo, q. v. Las novelas que menciona como publicadas por Agüeros salieron antes en el Año nuevo.

Leduc, Alberto, et al.

Diccionario de geografia, bistoria y biografia mexicanas (París, 1910), p. 830 .

Brevísima referencia a su vida y obra.

Mañón, Manuel

Historia del Teatro Principal de México (México, 1932), p. 84, 88,90 .

No contiene nada nuevo.

Marisçal, Mario

Ignacio Rodriguez Galván: un destino romántico. Filosofía y letras, núm. 7 (jul. / sep. 1942, México), p. 57-66.

Sumario de crítica y de biografía, pero falta una debida preparación bibliográfica al estudio. Se echa de ver que no cono- 
ció ciertas obras del poeta y ciertas fuentes biográficas. Sin embargo, es el estudio más amplio que tenemos, hasta la fecha, de las obras del poeta. Anuncia que este trabajo y una selección de composiciones de Galván van a salir en un tomo de la serie Biblioteca del estudiante universitario.

Menéndez y Pelayo, Marcelino

Antología de poetas bispano-americanos publicada por la Real Academia española, t. 1 (Madrid, 1927), p. cxiv-cxviii.

Desde luego, crítica autorizada. Lástima que no tuviese presente toda la producción poética del autor. Reproduce en las p. 90-106 la "Profecía de Guatimoc", a la que Llama "la obra maestra del romanticismo mexicano", y agrega que "si hubiera escrito siempre así, le faltaría poco para ser gran poeta".

$O$ [rtega], E[ulalio] M[aría]

Rodriguez Galván (D. Ignacio). Diccionario universal de bistoria y de geografía, t. 6 (México, 1855), p. 644-648.

Estudio fundamental en cuanto a la biografía y la crítica de Galván, hecho por un íntimo amigo suyo.

Pimentel, Francisco

Obras completas, t. 4 (México, 1903), p. 509-539.

Critica ampliamente todas las obras más importantes del poeta, pero lo hace desde su punto de vista de preceptista y positivista.

Prieto, Guillermo

Memorias de mis tiempos, 1828 a 1853 (México, 1906), t. 1, p. $126,128-30,184,187-188,213-214,217,271-272,337-338$, $360 ;$ t. 2, p. $5,65,81$.

Obra imprescindible para el estudio de la época y del autor. Era contemporáneo de Galván.

Reid, J. Lloyd

The Mexican bistorical novel 1826-1910 (Nueva York, 1939), p. 58-63.

Analiza los aspectos románticos de los dramas, pero no se da cuenta de que también era novelista.

Sánchez, Luis Alberto

Historia de la literatura americana (Santiago de Chile, 1937), p. $227,240,304$. 
Sosa, Francisco

Biografias de mexicanos distinguidos (México, 1884), p. 902905.

Biografía mediana.

Teatro Principal. El Apuntador (México, 1841), p. 72-73.

Revista teatral de la presentación de Muñoz, visitador de México, en el Teatro Principal, el 29 de junio de 1841. No se recibió muy bien. Dice el crítico: "el plan es bueno; buenos y sostenidos los caracteres; hermosa, flúida y correcta la versificación; atrevidos, nobles y aun sublimes los pensamientos; pero la acción es tarda, los diálogos largos, y alguno de ellos, aunque lleno de bellezas, no muy conducente: hablo del de Gonzalo y Celestina."

Torres-Rioseco, Arturo, y Warner, Ralph E.

Bibliografía de la poesía mexicana (Cambridge, Massachusetts, 1934), p. xv y 75 .

Citan las tres colecciones de poesías; brevísima critica.

Urbina, Luis G.

La vida literaria de México (Madrid, 1917), p. 152-155.

El lugar de Galván en el desarrollo de la literatura nacional: poetiza lo nacional.

Usigli, Rodolfo

México en el teatro (México, 1933), p. 73.

Referencia breve; retrato.

Zorrilla, José

La flor de los recuerdos (México, 1855), p. 449-52.

Breve mención; cita las poesías que le dedicaron a Galván cuando murió, Ramón Isaac Alcaraz y Guillermo Prieto.

Ernest Richard Moore, Oberlin College. 
